\title{
Appendicitis during the COVID-19 lockdown: results of a multicenter analysis in Germany
}

\author{
Arnulf G. Willms ${ }^{1}$ (D) Karl J. Oldhafer ${ }^{2} \cdot$ Sophie Conze ${ }^{1} \cdot$ Wolfgang E. Thasler ${ }^{3} \cdot$ Christian von Schassen $^{4}$. \\ Thorsten Hauer $^{5} \cdot$ Tobias Huber $^{6} \cdot$ Christoph-Thomas Germer $^{7}$. Simone Günster ${ }^{8}$. Dirk R. Bulian ${ }^{9} \cdot$ Zarah Hirche $^{10}$. \\ Jörg Filser ${ }^{11}$ - Gregor A. Stavrou ${ }^{12}$. Martin Reichert ${ }^{13} \cdot$ Patrizia Malkomes $^{14} \cdot$ Steffen Seyfried $^{15} \cdot$ Tobias Ludwig $^{16}$. \\ Hans C. Hillebrecht ${ }^{17}$. Dimitrios Pantelis ${ }^{18}$. Stefanie Brunner ${ }^{19} \cdot$ Wilm Rost $^{4} \cdot$ Johan F. Lock ${ }^{7}$. CAMIN Study Group
}

Received: 13 October 2020 / Accepted: 12 January 2021 / Published online: 7 February 2021

(C) The Author(s), under exclusive licence to Springer-Verlag GmbH, DE part of Springer Nature 2021

\begin{abstract}
Purpose The COVID-19 pandemic has transformed medical care worldwide. General surgery has been affected in elective procedures, yet the implications for emergency surgery are unclear. The current study analyzes the effect of the COVID-19 lockdown in spring 2020 on appendicitis treatment in Germany.

Methods Hospitals that provided emergency surgical care during the COVID-19 lockdown were invited to participate. All patients diagnosed with appendicitis during the lockdown period (10 weeks) and, as a comparison group, patients from the same period in 2019 were analyzed. Clinical and laboratory parameters, intraoperative and pathological findings, and postoperative outcomes were analyzed.

Results A total of 1915 appendectomies from 41 surgical departments in Germany were included. Compared to 2019 the number of appendectomies decreased by $13.5 \%$ (1.027 to $888, p=0.003)$ during the first 2020 COVID-19 lockdown. The delay between the onset of symptoms and medical consultation was substantially longer in the COVID-19 risk group and for the elderly. The rate of complicated appendicitis increased (58.2 to $64.4 \%$ ), while the absolute number of complicated appendicitis decreased from 597 to $569,(p=0.012)$. The rate of negative appendectomies decreased significantly ( 6.7 to $4.6 \% ; p=0.012)$. Overall postoperative morbidity and mortality, however, did not change.

Conclusion The COVID-19 lockdown had significant effects on abdominal emergency surgery in Germany. These seem to result from a stricter selection and a longer waiting time between the onset of symptoms and medical consultation for risk patients. However, the standard of emergency surgical care in Germany was maintained.
\end{abstract}

Keywords Appendicitis $\cdot$ COVID-19 $\cdot$ SARS-CoV-2 $\cdot$ Multicenter study $\cdot$ Complicated appendicitis $\cdot$ Emergency surgery

CAMIN: Surgical Working Group for Military and Emergency Surgery of the German Society for General and Visceral Surgery (DGAV) (a complete list of study contributors and centers can be found at the end of the article)

Comments This publication contains excerpts from Sophie Conze's doctoral thesis. The result of the reduction in appendectomies during the COVID-19 lockdown has been submitted as a letter to Deutsche Ärzteblatt.

Arnulf G. Willms

ArnulfWillms@bundeswehr.org

Extended author information available on the last page of the article

\section{Introduction}

The corona virus disease 2019 (COVID-19) pandemic has led to substantial changes in medical care worldwide [1-4]. International reports have shown an effect on emergency surgery $[5,6]$. Recently, Slagman et al. reported a reduction in medical emergencies by $13 \%$ when contact restrictions were in place [7].

Regardless of the pandemic, surgeons have to deal with surgical emergencies requiring time-critical surgical measures and emergency surgery in order to avoid substantial prognostic disadvantages [5, 8]. Appendicitis represents the most common emergency diagnosis in abdominal surgery and can be used to examine the effects of the COVID-19 pandemic on general emergency surgery [9-12]. Initial reports, editorials, 
and smaller, mostly single-center studies have shown a decreasing number of clinically treated appendicitis cases $[4$, $13,14]$ and an increase in disease severity [5, 15-18]. There has been no sufficient explanation for this phenomenon, since the incidence and severity of acute appendicitis do not appear to be related to the current pandemic or to the imposition of social restrictions.

The pandemic has posed additional challenges to emergency surgical care, which has responded in different ways. Conservative therapy options for appendicitis have become established in therapeutic algorithms [19,20]. Concerns about a possible risk of infection through aerosol formation during laparoscopy have brought open appendectomy back into focus [20-22]

The aim of this multicenter study is to analyze the different effects of the COVID-19 lockdown on a larger population with appendicitis in a multicenter setting.

\section{Methods}

Hospitals with continuous surgical emergency care during the COVID-19 lockdown were asked for participation. Hospitals with temporary restrictions on emergency care or with emergency coverage by external hospitals were excluded. Fortyone surgical departments participated and delivered their data by August 20,2020. Details concerning the care level and numbers of cases of participating hospitals are provided in Table 1.

\section{Study design}

The study was planned as a multicenter retrospective cohort study assessing appendicitis during the COVID-19 lockdown and a control group from the previous year. A 10-week interval starting between February and March 2020 with the regional lockdown, when restrictions on elective surgery and social distancing began, was compared with the same period in 2019.

The term "lockdown" stands for all social, medical, and organizational measures initiated by policymakers and the responsible decision-makers during this period. These measures

Table 1 Level of hospital care and number of patients

\begin{tabular}{lllll}
\hline Level & \multicolumn{2}{l}{ No. $(\%)$} & \multirow{2}{*}{$p$ value } \\
\cline { 2 - 4 } & Hospitals & Patients 2019 & Patients 2020 & \\
\hline University hospital & $13(31.7)$ & $327(31.8)$ & $281(31.6)$ & 0.52 \\
Tertiary & $6(14.6)$ & $170(16.6)$ & $157(17.7)$ & \\
Secondary & $16(39)$ & $423(41.2)$ & $343(38.6)$ & \\
Primary & $6(14.6)$ & $107(10.4)$ & $107(12.0)$ & \\
\hline
\end{tabular}

include contact restrictions and social distancing as well as restrictions on access to hospitals and the cancelation and postponement of elective surgery.

The study protocol was confirmed by the ethics committee of the administrative study centers of Würzburg (Ethikkommission der Universität Würzburg, No. 20200702 01) and Koblenz (Landesärztekammer Rheinland-Pfalz No.: 2020-15159). Several participating centers also obtained confirmation from their locally responsible review boards according to local obligations.

\section{Inclusion and exclusion criteria}

Patients with the diagnosis "K35" (acute appendicitis) according to the German Modification of the International Statistical Classification of Diseases (ICD-10-GM) who were treated surgically were included. Exclusion criteria were chronic appendicitis or other diseases of the appendix (ICD-10 codes K36-K38) and simultaneous appendectomy during abdominal operations because of other diseases.

\section{Collection of data}

The CAMIN (Surgical Working Group for Military and Emergency Surgery) Study Group of the German Society for General and Visceral Surgery (DGAV) prepared an anonymized database (Excel 2016, Microsoft, USA) containing various perioperative variables without allowing patient identification. The following variables were recorded as follows: age, gender, comorbidity (including the American Association of Anesthesiologists ASA score [23] and the Charlson comorbidity index [24]), symptoms of appendicitis (including the duration of symptoms prior to medical consultation, clinical signs, biochemical inflammation parameters, modified Alvarado score (MASS) [25]), intraoperative findings (including peritonitis, perforation, abscess and the Mannheimer Peritonitis Index [26]), a histopathological evaluation of appendicitis, and postoperative outcome (including length of stay (LOS), intensive-care-unit (ICU) utilization, and postoperative complications graded according to Clavien-Dindo [27]).

Data were collected from hospital information systems, internally validated, and transferred to a database. They were imported to IBM SPSS Statistics, Version 26, for statistical analysis. All variables were checked in detail for plausibility. Plausible entry errors were corrected; implausible data values were deleted.

\section{Diagnosis and patient management}

Patients with suspected appendicitis were given a standard clinical examination, a laboratory examination, which included at least a blood count and a CRP test, and an ultrasound examination of the abdomen. In $21.1 \%$ of the cases, an 
abdominal CT was performed and in $0,8 \%$ an abdominal MRI. At the first presentation, all patients were screened for COVID-19 infection using checklists developed in house. If the screening was positive, a smear was taken and a PCR test was conducted. If the result of the PCR test was positive at the time of the operation or was not yet available, surgeons and team members wore enhanced personal protective equipment (PPE), including an FFP2/FFP3 mask, protective goggles, and double gloves. Confirmed COVID-19 cases and suspected cases were isolated postoperatively. If the suspected cases tested negative, they were transferred to a normal surgical ward. Computed tomography imaging was performed on patients with possible COVID-19 symptoms.

\section{Statistical analysis}

All cases were categorized into three grades according to intraoperative and histopathological findings [11]:

- Negative appendectomy: no histological inflammation

- Uncomplicated appendicitis: histological phlegmonous appendicitis without perforation, abscess, or peritonitis

- Complicated appendicitis: histological gangrenous appendicitis, or periappendicitis, peritonitis, perforation, or abscess

To investigate the effect of the special contact restrictions on different population groups, we conducted subgroup analyses. The COVID-19 risk group was defined by the presence of defined risk factors such as age $\geq 70$ years, diabetes, immunosuppression, obstructive pulmonary disease, or a Charlson comorbidity score of $>3$ (moderate comorbidity) [28, 29], descriptive data are provided as mean values with standard deviation unless otherwise noted. Statistical tests were applied according to the data distribution using the Wilcoxon rank-sum test for matched samples, the MannWhitney $U$ test for independent samples, and the chisquared test for categorical variables. $p$ values $<0.05$ were regarded as statistically significant.

\section{Results}

\section{Incidence of appendicitis}

The starting day of the 10 -week study period varied between February 25 and March 27, depending upon local COVID-19 restrictions. The overall number of patients decreased from 1027 in 2019 to $888(-13.5 \%, p=0.003)$ during the COVID-19 lockdown. The distribution of patients between hospitals and the level of care was unchanged (Table 1). Detailed baseline patient characteristics are summarized in Table 2. No differences in baseline characteristics were found during the COVID-19 lockdown.

\section{Clinical presentation}

The duration of symptoms before medical presentation was $24 \mathrm{~h}$ in median, both in 2019 and 2020 (Table 3). In addition, the proportion of patients with late presentation $(>48 \mathrm{~h}$ ) did not differ $(29.9 \%$ vs. $32.1 \%, p=0.30)$. However, the subgroup of COVID-19 risk patients presented significantly later after the onset of symptoms during the lockdown (Fig. 1a). The percentage of late presentation was significantly higher (28.3\% vs. $46.4 \%, p=0.004)$. Similar results were observed for elderly patients (Fig. 1b). The lockdown had no effect on the time between the onset of symptoms and presentation in hospital in other subgroups.

The likelihood of appendicitis as determined by MASS was significantly higher during the lockdown. The leukocyte count was also higher. When it came to the question of when the indication for surgery was decided, there was a trend toward prompt indication on admission as opposed to in-patient observation (Table 3$)$.

Six percent $(53 / 888)$ of the patients were suspected of having COVID-19 at the time of the operation and $0.3 \%(3 / 888)$ eventually tested positive for SARS-CoV-2. Of these, one was asymptomatic, and two had mild symptoms.

Table 2 Patient characteristics

\begin{tabular}{llll}
\hline Variable & No. $(\%)$ & & $p$ value \\
\hline Year & 2019 & 2020 & \\
$n=$ & 1027 & 888 & $\mathbf{0 . 0 0 3}$ \\
Sex; m:f & $510: 517$ & $468: 420$ & 0.18 \\
Age, y, mean \pm SD & $35 \pm 19$ & $36 \pm 20$ & 0.24 \\
Children, < 18 years & $174(16.9)$ & $151(17.0)$ & 0.97 \\
Elderly, $\geq 75$ years & $41(4.0)$ & $43(4.8)$ & 0.37 \\
Obesity, BMI $>30 \mathrm{~kg} / \mathrm{m}^{2}$ & $138(15.3)$ & $132(17.0)$ & 0.36 \\
Comorbidity ${ }^{1}$ & & & 0.95 \\
None, CCI 0 & $831(84.0)$ & $710(83.7)$ & \\
Minor, CCI 1-2 & $104(10.5)$ & $93(11.0)$ & \\
Moderate, CCI 3-4 & $31(3.1)$ & $28(3.3)$ & \\
Major, CCI $\geq 5$ & $23(2.3)$ & $17(2.0)$ & \\
ASA score & & & 0.41 \\
1 & $545(54.2)$ & $447(51.9)$ & \\
2 & $375(37.3)$ & $328(38.1)$ & \\
3 & $75(7.5)$ & $80(9.3)$ & \\
4 & $10(1.0)$ & $6(0.7)$ & \\
COVID-19 risk group ${ }^{2}$ & $120(11.7)$ & $112(12.6)$ & 0.54 \\
\hline
\end{tabular}

mean $\pm S D$, mean \pm standard deviation; $A S A$, American Association of Anesthesiologists Score; $C C I$, Charlson comorbidity index; ${ }^{1}$ according to the Charlson comorbidity index; ${ }^{2}$ the COVID-19 risk group was defined as age $\geq 70$ years, or risk factors such as diabetes, immunosuppression, obstructive pulmonary disease, or $\mathrm{CCI} \geq 3$ 
Table 3 Preoperative assessment and indication for surgery

\begin{tabular}{llll}
\hline Variable & No. $(\%)$ & & $p$ value \\
\hline Year & 2019 & 2020 & \\
Duration of complaints, h, mean \pm SD (median) & $37.5 \pm 45.8(24)$ & $40.1 \pm 55.9(24)$ & 0.24 \\
$\geq 48$ h & $307(29.9)$ & $285(32.1)$ & 0.30 \\
Pain, VAS, mean \pm SD & $5.5 \pm 1.9$ & $5.3 \pm 1.8$ & 0.13 \\
Modified Alvarado score & & & $\mathbf{0 . 0 2 8}$ \\
$1-3$ (unlikely) & $242(26.9)$ & $184(22.7)$ & \\
$4-6$ (compatible) & $437(48.5)$ & $386(47.7)$ & \\
$7-8$ (probable) & $189(20.0)$ & $181(22.3)$ & \\
9 (very probable) & $42(4.7)$ & $59(7.3)$ & $\mathbf{0 . 0 0 4}$ \\
Leukocytes, /nl, mean \pm SD & $12.9 \pm 4.6$ & $13.6 \pm 5.4$ & 0.058 \\
CRP, mg/l, mean \pm SD & $60.5 \pm 87.6$ & $60.7 \pm 80.6$ & \\
Indication for surgery & & & \\
After inpatient observation & $220(21.4)$ & $159(17.9)$ & 0.056 \\
Immediately on admission & $806(78.6)$ & $727(82.1)$ & \\
\hline
\end{tabular}

mean $\pm S D$, mean \pm standard deviation; $V A S$, visual analog pain scale; $C R P$, C-reactive protein

\section{Severity of appendicitis}

Table 4 presents the intraoperative and histopathological findings in detail. While the relative overall incidence of negative appendectomies decreased to $4.6 \%$, the rate of complicated
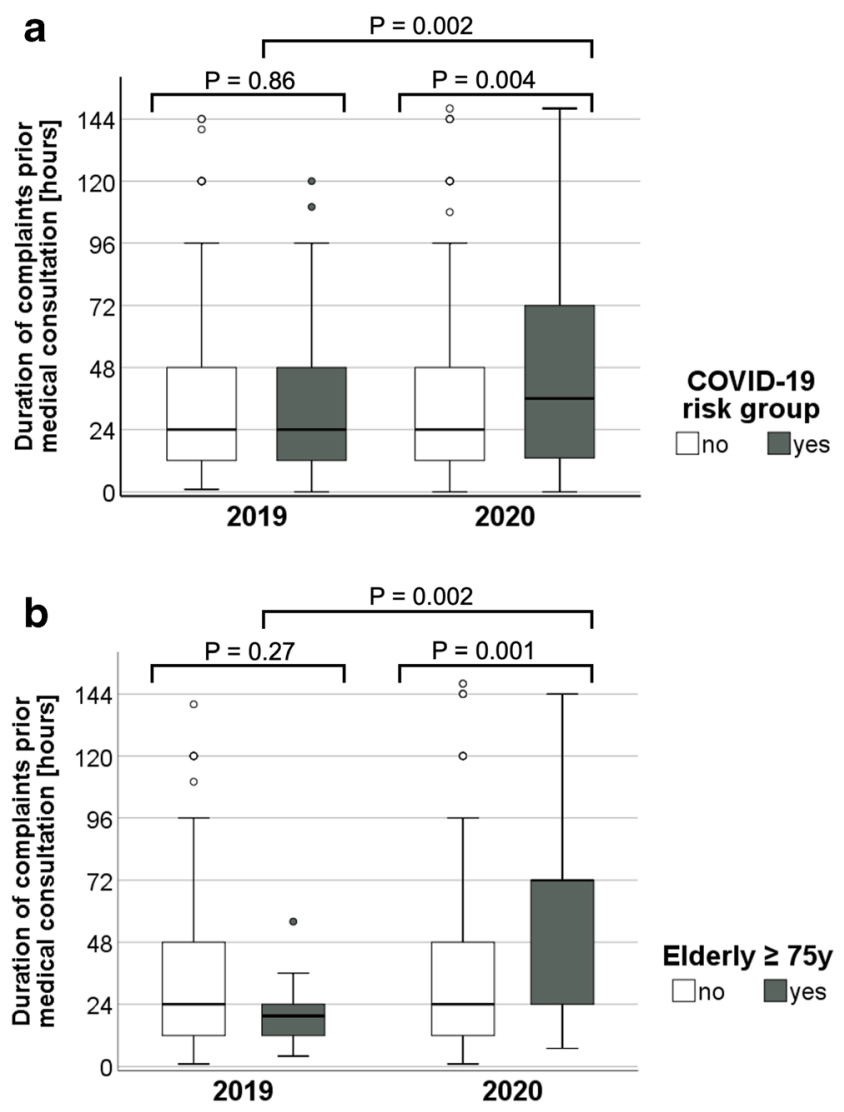

Fig. 1 Duration of symptoms prior to medical consultation. a In COVID19 risk group. b In elderly patients $\geq 75$ years appendicitis rose to $64.4 \%(p=0.012)$ during the lockdown. However, the likelihood of perforation or peritonitis did not increase significantly in this period and the absolute number of complicated appendicitis even decreased from 597 to 569.

General factors affecting disease severity were analyzed during the control interval in 2019. Negative appendectomies were more common in female patients $(8.9 \%$ vs. $4.5 \%$, $p=0.001)$ and children (9.2\% vs. $6.2 \%, p=0.026)$. Complicated appendicitis occurred more often in patients in the COVID-19 risk group ( $80.8 \%$ vs. $55.2 \%, p<0.001)$ with the highest incidence in elderly patients $(87.8 \%$ vs. $57.0 \%$, $p=0.002$ ).

In the subgroups analyzed, different trends were detected during the lockdown in 2020. The rate of negative appendectomy decreased in females from $8.9 \%$ to $5.5 \%(p=0.013)$ and in children from 9.2 to $2.6 \%(p=0.009)$. The percentage of complicated appendicitis remained similarly high in patients in the COVID-19 risk group $(80.8 \%$ and $81.8 \% ; p=0.68)$ and elderly patients $(87.8 \%$ and $88.4 \% ; p=0.60)$. The relative overall increase in complicated appendicitis can thus be attributed to the non-COVID-19 risk group (55.2\% to $61.9 \%$, $p=0.003$ ).

Table 4 Severity of appendicitis

\begin{tabular}{llll}
\hline Variable & No. (\%) & & $p$ value \\
\hline Year & 2019 & 2020 & \\
Negative appendectomy $^{1}$ & $69(6.7)$ & $41(4.6)$ & $\mathbf{0 . 0 1 2}$ \\
Uncomplicated appendicitis $^{1}$ & $359(35.0)$ & $274(31.0)$ & \\
Complicated appendicitis $^{2}$ & $597(58.2)$ & $569(64.4)$ & \\
\hline
\end{tabular}

${ }^{1} \mathrm{Phlegmonous} \mathrm{appendicitis} \mathrm{without} \mathrm{perforation,} \mathrm{abscess,} \mathrm{or} \mathrm{peritonitis;}$ ${ }^{2}$ gangrenous appendicitis or periappendicitis, peritonitis, perforation, or abscess 


\section{Postoperative outcome}

No overall differences in postoperative outcome, including the risk of complications, mortality, or LOS, were observed during the lockdown (Table 5). Long waits before presentation (> $48 \mathrm{~h}$ ) were associated with an increased risk of severe postoperative complications in both years (2019: $7.2 \%$ vs. $2.8 \%, p<0.001$; 2020: $7.4 \%$ vs. $1.8 \%, p<0.001)$. Patients belonging to the COVID-19 risk group showed an overall increased risk of major postoperative complications $(12.5 \%$ vs. $2.7 \% ; p<0.001)$ and a need for ICU therapy $(17.9 \%$ vs. $2.3 \% ; p<0.001)$ in comparison to non-risk-group patients as we suspected. Nevertheless, no increases in morbidity in general or in mortality did occur during the lockdown period in this group.

No differences were observed within the analyzed time frames of Clavien-Dindo classification subgroups. Grade IIIa complications were intraabdominal collections requiring percutaneous drainage in 8 of 9 patients, a single case of gastrointestinal bleeding and endoscopy occurred in 2020 . Reoperations (grade IIIb) were performed for anastomotic/ suture leakage (6 patients), persisting peritonitis/ abcess formation (18 patients), postoperative bleeding (4 patients), fascial dehiscence ( 5 patients), urinary leakage (1 patient), and obstructive ileus (5 patients).

Neither an operation on a suspected COVID-19 case nor positive evidence of SARS-CoV-2 infection had a significant effect on prognosis.

\section{Discussion}

Besides representing a significant medical and political challenge, the COVID-19 pandemic is also an opportunity to gain new insights into the course of diseases and treatment options. Especially in emergency surgery, adequate care needs to be delivered despite of the pandemic situation.

Our representative analysis of appendicitis in Germany clearly indicates that the COVID-19 pandemic has affected emergency surgical care. Overall, fewer appendectomies were performed. Histopathological findings, perforations, abscesses, higher stages of inflammation, clinical signs with higher modified Alvarado scores, and leukocytosis indicate a higher rate of more severe disease courses in relation to the whole included patient population. While the rate of complicated appendicitis increased, the absolute number of complicated appendicitis decreased in the whole cohort. The qualitative and quantitative changes were initially due to two circumstances: there were fewer negative appendectomies, and the relative proportion of complicated appendectomies has increased.

In theory, there may be two explanations for these changes. Firstly, it can be hypothesized that patients' fear of an inhospital COVID-19 infection leads to a different selection because they hesitate to contact a surgeon. During this delay,
Table 5 Postoperative outcome

\begin{tabular}{llll}
\hline Variable & No. $(\%)$ & & $p$ value \\
\hline Year & 2019 & 2020 & \\
Postoperative complications $^{1}$ & & & 0.46 \\
None & $891(86.8)$ & $759(85.7)$ & \\
Grade I-II & $94(9.2)$ & $95(10.7)$ & \\
Grade III-V & $42(4.1)$ & $32(3.6)$ & \\
In-hospital mortality & $2(0.2)$ & $1(0.1)$ & 0.99 \\
LOS, $d$, mean \pm SD & $4.5 \pm 4.1$ & $4.6 \pm 4.0$ & 0.85 \\
ICU stay n & $39(3.9)$ & $39(4.5)$ & 0.53 \\
\hline
\end{tabular}

$L O S$, length-of-stay; mean $\pm S D$, mean \pm standard deviation; $I C U$, intensive-care-unit

${ }^{1}$ According to Clavien-Dindo

the inflammation progresses or a self-limiting course may occur. The different selection is supported by the significant decrease in negative appendectomies on the one hand and the longer time to presentation in the group of patients defined as a population at risk concerning the severity of the course of a possible COVID-19 infection on the other hand [28, 29]. Secondly, the scarcity of resources and prioritization could have led to changed in-hospital processes.

According to their analysis of data from 36 emergency rooms, Slagman et al. also noticed a significant decrease in medical emergencies in all disciplines since the introduction of contact restrictions during the COVID-19 pandemic [7]. As in the current analyses, a decrease of $13 \%$ was obtained.

The decrease in the total number of appendicitis cases is greater than the increase in complicated appendicitis cases. This may be explained by the reduction in the number of negative appendectomies and uncomplicated courses.

When it comes to reducing collateral damage and prognostic disadvantages caused by the pandemic, a key role is played by dedicated patient education and by ensuring the least possible changes to emergency surgical care [30]. It is undoubtedly essential to emphasize that, in the changed clinical care situation as a result of the pandemic measures, it is crucial to identify patients requiring an emergency operation without delay despite changed circumstances [5].

The present evaluation shows that, at the time of the national COVID-19 lockdown, almost $80 \%$ of the patients in both groups were operated on immediately and about $20 \%$ after initial clinical observation. The higher disease severity and the more pronounced symptoms explain why more patients were operated on directly in 2020. Despite progressive inflammation and increased appendicitis complications in 2020, there were no significant differences in clinical outcomes. Overall, the standard of emergency surgical care in Germany was maintained despite pandemic-related restrictions. 
However, the usually low rate of very complicated cases of appendicitis does not allow an uncritical extrapolation of the current results to other surgical emergencies. A comparison with the international literature shows some parallels regarding a reduction in appendectomies [13, 14], a later presentation, and an increased inflammatory reaction $[5,15-18,20,31]$. The international survey of Ielpo et al. of more than 700 surgeons worldwide reported a decrease of appendicitis and an increase of complicated cases based on a questionnaire [20].

In contrast to the current analysis, where patient outcome was unaffected despite the increased severity, Cano-Valderrama et al. found a decrease in emergency surgery activity but an increase in mortality and thus a worse outcome [32].

The obtained data further allow interpretations about the disease of acute appendicitis, which is not yet understood in detail $[9,11]$. The reduction in the total number of appendectomies may be due to fewer negative and uncomplicated appendectomies as a result of two potential factors: a restricted presentation of patients with mild symptoms or a more restricted selection of the presenting patients who undergo in-house observation or exploration.

Based on this study and on the findings of other studies, there are three possible courses: a self-limiting, a conservative treatable, and a progressive course. The latter can only be safely managed by an emergency operation.

The antibiotic treatment of uncomplicated appendicitis has moved more into focus due to the pandemic [19, 33]. In our opinion, there are two objections to a general recommendation in this regard. First, the diagnosis of uncomplicated appendicitis often requires computed tomography, which is accompanied by radiation exposure. Second, there is often a recurrence of inflammation with a possibly complicated course [34].

It is currently impossible to predict patient courses or to exactly define the influencing factors [11]. A meta-analysis by Harnoss et al. from 2017 concluded that even if antibiotics prevent some patients from undergoing appendectomy at the initial presentation, surgery represents the definitive treatment of choice [35].

The long-term impact of antibiotic treatment for appendicitis is unclear due to the high recurrence rate and the possibility of complicated courses. The findings of the present study suggest that the best emergency surgery care was maintained without changing the general treatment algorithm for appendicitis and without risking free intensive care beds for COVID patients. The decrease in appendicitis cases in 2020 in our study was accompanied by a decrease in the rate of negative appendectomies. These cases may have been selflimiting or successfully treated with antibiotics and may not have been included in the current analysis.

However, conservative antibiotic treatment may be carried out on a case-by-case basis for patients in poor general health who are unfit for surgery [20]. The prerequisite would be appropriate imaging to rule out a perforation or abscess.
This could also be an alternative of choice in order to reduce intra-hospital overload in times of health crises and limited resources [33].

All comparisons with available international studies are fundamentally limited on account of several factors. Germany experienced a comparatively mild pandemic and had excellent preexisting medical resources. Other countries faced a much more dynamic pandemic situation with reduced medical resources. The studies consider different collectives and sometimes different observation periods. Finally, the present multicenter study was only subjected to internal and not external data validation.

\section{Limitations}

This study is a retrospective study with all the immanent limitations in which some surgical clinics in Germany (approximately 4\%) took part. Also, based on the inclusion criteria, it is limited to patients with confirmed appendicitis who had undergone surgical treatment.

\section{Conclusion}

The COVID-19 lockdown significantly impacted abdominal emergency surgery in Germany and led to a $13 \%$ reduction in appendectomies. With it, the rate of complicated appendicitis increased significantly while their absolute number deceased and negative appendectomies decreased significantly as well. Potential causes could be a relevant number of self-limiting mild appendicitis cases that recovered without medical presentation and a longer waiting time between the onset of symptoms and the medical consultation of risk patients. The standard of emergency surgery in Germany was maintained during the pandemic, and there were neither longer waiting times for operations nor a diminished outcome for patients.

Supplementary Information The online version contains supplementary material available at https://doi.org/10.1007/s00423-021-02090-3.

Acknowledgements We would like to thank all personnel of the 41 study centers who contributed to data acquisition and validation. We would like to thank the DGAV for supporting the current study.

CAMIN study group Authors: Arnulf G. Willms, Karl J. Oldhafer, Sophie Conze, Wolfgang E. Thasler, Christian von Schassen, Thorsten Hauer, Tobias Huber, Christoph-Thomas Germer, Simone Günster, Dirk R. Bulian, Zarah Hirche, Jörg Filser, Gregor A. Stavrou, Martin Reichert, Patrizia Malkomes, Steffen Seyfried, Tobias Ludwig, Hans C. Hillebrecht, Dimitrios Pantelis, Stefanie Brunner, Wilm Rost, Johan F. Lock, CAMIN Study Group

CAMIN Board: Prof. Dr. med. Karl J. Oldhafer (chairman); Lt. Col. Dr. med. Thorsten Hauer (2nd chairman); Lt. Col. PD Dr. med. Arnulf Willms (secretary); Prof. Dr. med. Christoph-Thomas Germer (assessor); 
Prof. Dr. med. Wolfgang E. Thasler (assessor); PD Dr. med. Johan F. Lock (assessor)

Contributors Klinik für Allgemein-, Viszeral- und Thoraxchirurgie, InnKlinikum Altötting und Mühldorf, Altötting: Prof. Dr. med. Christian Jurowich, Dr. med. Jörg Filser, Julia Gozzer

Klinik für Allgemeine Chirurgie/Viszeralchirurgie, Zentralklinik Bad Berka, Bad Berka: Prof. Dr. med. Merten Hommann, PD Dr. med. Daniel Kaemmerer,

Klinik für Allgemein- und Viszeralchirugie, St. Joseph Krankenhaus Berlin-Tempelhof, Berlin: Prof. Dr. med. Jörn Gröne, Dr. med. Lope Estévez Schwarz

Klinik für Allgemein-, Viszeral- und Thoraxchirurgie, Bundeswehrkrankenhaus Berlin, Berlin: Dr. med. Niels Huschitt, Dr. med. Thorsten Hauer, Dr. med. Alexander Abazid

Abteilung für Allgemein- und Viszeralchirurgie, GFO Kliniken Bonn, Bonn: Prof. Dr. med. Dimitrios Pantelis

Klinik und Poliklinik für Allgemein-, Viszeral-, Thorax- und Gefäßchirurgie, Universitätsklinikum Bonn, Bonn: Prof. Dr. med. Jörg C. Kalff, PD Dr. med. Martin von Websky, Dr. med. Philipp Lingohr, Philipp Feodorovici

Klinik für Chirurgie, Klinikum Dortmund, Dortmund: Prof. Dr. med. Maximilian Schmeding, Dr. med. Jonas Linnemann

Klinik für Allgemein- und Visceralchirurgie, Sana Krankenhaus Benrath, Düsseldorf: Prof. Dr. med. Claus Franke

Klinik für Allgemein-, Viszeral- und Kinderchirurgie, Universitätsklinikum Düsseldorf, Düsseldorf: Prof. Dr. med. Wolfram

T. Knoefel, PD Dr. med. Georg Flügen

Chirurgische Klinik, Universitätsklinikum Erlangen, Erlangen: Prof.

Dr. med. Robert Grützmann, Dr. med. Henriette Golcher

Klinik für Allgemein-, Viszeral- und Transplantationschirurgie, Universitätsklinikum Frankfurt, Frankfurt: Prof. Dr. med. Wolf O. Bechstein, Prof. Dr. med. Andreas Schnitzbauer, Dr. med. Patrizia Malkomes

Klinik für Allgemein- und Viszeralchirurgie, Universitätsklinikum Freiburg, Freiburg: Prof. Dr. med. Stefan Fichtner-Feigl, Dr. med. Dominik Jauch, Hans C. Hillebrecht

Operatives Zentrum für Allgemeinchirurgie, Klinikum Fürth, Fürth: PD Dr. med. Katica Krajinovic, Dr. med. Simone Günster

Klinik für Allgemein-, Viszeral-, Thorax-, Transplantations- und Kinderchirurgie, Universitätsklinikum Gießen, Gießen: Prof. Dr. med. Winfried Padberg, PD Dr. med. Andreas Hecker, Dr. med. Martin Reichert

Abteilung für Allgemein- und Viszeral-, und Gefäßchirurgie, Asklepios Klinik Altona, Hamburg: Prof. Dr. med. Gero Puhl, Dr. med. Henning Albrecht, Dr. med. Dominik Richter

Klinik für Leber-, Gallenwegs- und Pankreaschirurgie, Asklepios Klinik Barmbeck, Hamburg: Prof. Dr. med. Karl Oldhafer, Valery Danwe Koukreo

Klinik für Allgemein- und Viszeralchirurgie, Asklepios Klinik NordHeidberg, Hamburg: PD Dr. med. Asad Kutup, Dr. med. Elmar Mehring, Dr. A. Ghadim Khani

Abteilung für Allgemein- und Viszeralchirurgie, Asklepios Klinik Wandsbek, Hamburg: PD Dr. med. Dean Bogoevski, Johannes Erbes, Stefan Nikolovski

Klinik für Allgemein- Viszeral- und Thoraxchirurgie, Bundeswehrkrankenhaus Hamburg, Hamburg: Dr. med. Wilm Rost, Dr. med Christian von Schassen

Klinik für Allgemein-, Viszeral- und onkologische Chirurgie, St. Bernward Krankenhaus, Hildesheim: Prof. Dr. med. Jörg Pelz

Klinik für Allgemein-, Viszeral-, Gefäß- und Thoraxchirurgie, Klinikum Kaufbeuren, Kaufbeuren: Prof. Dr. med. Stefan Maier, Christoph Berghammer, Sabine Michling

Klinik für Allgemein- und Viszeralchirurgie, Thoraxchirurgie, Bundeswehrzentralkrankenhaus Koblenz, Koblenz: Prof. Dr. med. Robert Schwab, PD. Dr. med. Arnulf Willms, Dr. med. Christoph Güsgen, Sophie Conze

Klinik für Viszeral-, Tumor-, Transplantations- und Gefäßchirurgie, Kliniken der Stadt Köln, Standorte Merheim und Holweide, Köln: PD Dr. med. Dirk R. Bulian Prof. Dr. med. Markus M. Heiss, Prof. Dr. med. Claus F. Eisenberger

Klinik und Poliklinik für Allgemein-, Viszeral-, Tumor- und Transplantationschirurgie, Uniklinik Köln, Köln: Prof. Dr. med. Christiane Bruns, Dr. med. Stefanie Brunner

Chirurgie II Allgemein- und Viszeralchirurgie, St. Vinzenz-Hospital, Köln-Nippes: Dr. med. Thomas Wilhelm, Anke Esmann

Klinik und Poliklinik für Viszeral-, Transplantations-, Thorax- und Gefäßchirurgie, Klinik für Kinderchirurgie, Universitätsklinikum Leipzig, Leipzig: Prof. Dr. med. Ines Gockel, Prof. Dr. med. Martin Lacher, Nicole Kreuser, Dr. med. Nikolaus von Dercks, Sandra Strauß

Klinik für Allgemein-, Viszeral- und Thoraxchirurgie, Klinikum Ludwigshafen am Rhein, Ludwigshafen: Prof. Dr. med. Stefan Willis, PD Dr. med. Zarah Hirche

Klinik für Allgemein-, Viszeral- und Gefäßchirurgie, Evangelisches Krankenhaus Paul Gerhardt Stift, Lutherstadt Wittenberg: Prof. Dr. med. Martin Stockmann, Adrian Vegue Alvarez

Klinik für Allgemein-, Viszeral-und Transplantationschirurgie, Universitätsmedizin Mainz, Mainz: Prof. Dr. med. Hauke Lang, PD Dr. med. Tobias Huber, Dr. med. Nicolas Wachter, Dr. med. Christian Boedecker

Chirurgische Klinik, Universitätsmedizin Mannheim, Mannheim: Prof. Dr. med. Christoph Reissfelder, Dr. med. Steffen Seyfried

Klinik für Allgemein,- Viszeral,- Thorax- und Gefässchirurgie, Klinikum Memmingen, Memmingen: Prof. Dr. med. Carsten N. Gutt, Dr. med. Robert C. Grabensee, Roberta Birkas-Kovats

Abteilung für Allgemein-, Viszeral-, Thorax- und Minimalinvasive Chirurgie, Rot-Kreuz-Klinikum München, München: Prof. Dr. med. Wolfgang Thasler

Klinik für Allgemein-, Viszeral- und Gefäßchirurgie, KRH Klinikum, Neustadt am Rübenberge: Dr. med. Stephan Kaaden, Ingo Gerstmann

Klinik für Allgemein- Viszeral- und Thoraxchirurgie, Klinikum Osnabrück, Osnabrück: PD Dr. med. Jürgen Tepel

Abteilung für Allgemein-, Viszeral-, Gefäß- und Transplantationschirurgie, Universitätsmedizin Rostock, Rostock: Prof. Dr. med. Clemens Schafmayer, Dr. med. Alexander Hendricks, Tobias Ludwig

Klinik für Allgemein- und Viszeralchirurgie, Thoraxchirurgie, Chirurgische Onkologie, Klinikum Saarbrücken, Saarbrücken: Dr.med Dr.habil Gregor A. Stavrou, Mahmoud Jabal, Kira Keller

Chirurgische Klinik, Leopoldina Krankenhaus, Schweinfurt: Prof. Dr. med. Detlef Meyer, Andreas Schmidt, Konrad Poker

Klinik für Allgemein- Viszeral- und Thoraxchirurgie, Bundeswehrkrankenhaus Ulm, Ulm: Prof. Dr. med. Roland Schmidt, Dr. med. Christian Beltzer

Klinik für Allgemein-, Visceralchirurgie und Proktologie, Asklepios Klinik Weißenfels, Weißenfels: Dr. med. Ralf Wilke

Klinik für Chirurgie - Allgemein- und Viszeralchirurgie, Klinikum Würzburg Mitte, Würzburg: Prof. Dr. med. Ulrich Steger

Klinik und Poliklinik für Allgemein-, Viszeral-, Transplantations-, Gefäß- und Kinderchirurgie, Universitätsklinikum Würzburg, Würzburg: Prof. Dr. med. Christoph-Thomas Germer, PD Dr. med. Armin Wiegering, PD Dr. med. Johan Friso Lock, Dr. med. Agnes Treutlein

Authors' contributions The CAMIN board and WR had the study idea and defined the methodology. All Authors contributed all their cases during the defined time frame and revised the first version of the manuscript. AGW, JFL, SC, and KJO performed the analysis and wrote the manuscript.

\section{Declarations}

Ethics approval and consent to participate All procedures performed in studies involving human participants were in accordance with the ethical standards of the institutional and/or national research committee and with the 1964 Helsinki declaration and its later amendments or comparable 
ethical standards. According to the responsible ethics committees, there is no need for informed consent due to the retrospective anonymous character of the study, which is isolated based on existing hospital documentation systems and without the need for further data acquisition or any study-related contact to the patient.

Competing interests The authors declare no competing interests.

\section{References}

1. (WHO) WHO (2020) WHO Timeline - COVID-19 https://www. who.int/news-room/detail/27-04-2020-who-timeline\%2D\%2Dcovid-19

2. (WHO) WHO (2020) WHO director general's opening remarks at the media briefing on COVID 1911 march 2020. https://www.who. $\mathrm{int} / \mathrm{dg} / \mathrm{speeches/detail/who-director-general-s-opening-remarks-at-}$ the-media-briefing-on-covid-19\%2D\%2D-11-march-2020

3. Di Saverio S, Pata F, Gallo G, Carrano F, Scorza A, Sileri P, Smart N, Spinelli A, Pellino G (2020) Coronavirus pandemic and colorectal surgery: practical advice based on the Italian experience. Color Dis 22(6):625-634. https://doi.org/10.1111/codi.15056

4. Jahne $J(2020)$ The Corona crisis and its consequences for surgery. Chirurg 91(5):432-434. https://doi.org/10.1007/s00104-02001182-y

5. Dick L, Green J, Brown J, Kennedy E, Cassidy R, Othman S, Berlansky M (2020) Changes in emergency general surgery during covid-19 in Scotland: a prospective cohort study. World J Surg 44: 3590-3594. https://doi.org/10.1007/s00268-020-05760-3

6. Soreide K, Hallet J, Matthews JB, Schnitzbauer AA, Line PD, Lai PBS, Otero J, Callegaro D, Warner SG, Baxter NN, Teh CSC, NgKamstra J, Meara JG, Hagander L, Lorenzon L (2020) Immediate and long-term impact of the COVID-19 pandemic on delivery of surgical services. Br J Surg. https://doi.org/10.1002/bjs.11670

7. Slagman A, Behringer W, Greiner F, Klein M, Weismann D, Erdmann B, Pigorsch M, Mockel M, Registry AED, German Forum of University Emergency Departments in the Society of University Clinics of Germany EV (2020) Medical emergencies during the covid-19 pandemic. Dtsch Arztebl Int 117(33-34):545552. https://doi.org/10.3238/arztebl.2020.0545

8. Parreira JG, Campos T, Antunes PSL, Perlingeiro JAG, Assef JC (2020) Management of non traumatic surgical emergencies during the COVID-19 pandemia. Rev Col Bras Cir 47:e20202614. https:// doi.org/10.1590/0100-6991e-20202614

9. Andric M, Kalff JC, Schwenk W, Farkas S, Hartwig W, Turler A, Croner R (2020) Recommendations on treatment of acute appendicitis : recommendations of an expert group based on the current literature. Chirurg 91(9):700-711. https://doi.org/10.1007/s00104020-01237-0

10. Baum P, Diers J, Lichthardt S, Kastner C, Schlegel N, Germer CT, Wiegering A (2019) Mortality and complications following visceral surgery: a nationwide analysis based on the diagnostic categories used in German hospital invoicing data. Dtsch Arztebl Int 116(44): 739-746. https://doi.org/10.3238/arztebl.2019.0739

11. Bhangu A, Soreide K, Di Saverio S, Assarsson JH, Drake FT (2015) Acute appendicitis: modern understanding of pathogenesis, diagnosis, and management. Lancet 386(10000):1278-1287. https://doi.org/10.1016/S0140-6736(15)00275-5

12. Ferris M, Quan S, Kaplan BS, Molodecky N, Ball CG, Chernoff GW, Bhala N, Ghosh S, Dixon E, Ng S, Kaplan GG (2017) The global incidence of appendicitis: a systematic review of populationbased studies. Ann Surg 266(2):237-241. https://doi.org/10.1097/ SLA.0000000000002188
13. English W, Habib Bedwani N, Smith C, Shatkar V (2020) Investigation and management of suspected appendicitis during the COVID-19 pandemic. Br J Surg 107:e337-e338. https://doi. org/10.1002/bjs. 11787

14. Tankel J, Keinan A, Blich O, Koussa M, Helou B, Shay S, Zugayar D, Pikarsky A, Mazeh H, Spira R, Reissman P (2020) The decreasing incidence of acute appendicitis during COVID-19: a retrospective multi-centre study. World J Surg 44(8):2458-2463. https://doi. org/10.1007/s00268-020-05599-8

15. Romero J, Valencia S, Guerrero A (2020) Acute appendicitis during coronavirus disease 2019 (COVID-19): changes in clinical presentation and CT findings. J Am Coll Radiol 17(8):1011-1013. https://doi.org/10.1016/j.jacr.2020.06.002

16. Snapiri O, Rosenberg Danziger C, Krause I, Kravarusic D, Yulevich A, Balla U, Bilavsky E (2020) Delayed diagnosis of paediatric appendicitis during the COVID-19 pandemic. Acta Paediatr 109(8):1672-1676. https://doi.org/10.1111/apa.15376

17. Velayos M, Munoz-Serrano AJ, Estefania-Fernandez K, Sarmiento Caldas MC, Moratilla Lapena L, Lopez-Santamaria M, LopezGutierrez JC (2020) Influence of the coronavirus 2 (SARS-Cov-2) pandemic on acute appendicitis. An Pediatr (Engl Ed) 93:118-122. https://doi.org/10.1016/j.anpede.2020.04.010

18. Fisher JC, Tomita SS, Ginsburg HB, Gordon A, Walker D, Kuenzler KA (2020) Increase in pediatric perforated appendicitis in the New York city metropolitan region at the epicenter of the COVID-19 outbreak. Ann Surg Publish Ahead of Print. https://doi. org/10.1097/SLA.0000000000004426

19. Javanmard-Emamghissi H, Boyd-Carson H, Hollyman M, Doleman B, Adiamah A, Lund JN, Clifford R, Dickerson L, Richards S, Pearce L, Cornish J, Hare S, Lockwood S, Moug SJ, Tierney GM, Group CHC (2020) The management of adult appendicitis during the COVID-19 pandemic: an interim analysis of a UK cohort study. Tech Coloproctol. https://doi.org/10.1007/ s10151-020-02297-4

20. Ielpo B PM, Pellino G, Pata F, Caruso R, Gravante G, Di Saverio S; ACIE Appy Study Collaborative (2020) Global attitudes in the management of acute appendicitis during COVID-19 pandemic: ACIE Appy Study. Accessed 108

21. Mowbray NG, Ansell J, Horwood J, Cornish J, Rizkallah P, Parker A, Wall P, Spinelli A, Torkington J (2020) Safe management of surgical smoke in the age of COVID-19. Br J Surg. https://doi.org/ 10.1002/bjs. 11679

22. Scott C, Lambert A (2020) Managing appendicitis during the COVID-19 pandemic in the UK. Br J Surg 107(8):e271. https:// doi.org/10.1002/bjs.11752

23. Owens WD, Felts JA, Spitznagel EL Jr (1978) ASA physical status classifications: a study of consistency of ratings. Anesthesiology 49(4):239-243. https://doi.org/10.1097/00000542-19781000000003

24. Charlson ME, Pompei P, Ales KL, MacKenzie CR (1987) A new method of classifying prognostic comorbidity in longitudinal studies: development and validation. J Chronic Dis 40(5):373-383. https://doi.org/10.1016/0021-9681(87)90171-8

25. Kalan M, Talbot D, Cunliffe WJ, Rich AJ (1994) Evaluation of the modified Alvarado score in the diagnosis of acute appendicitis: a prospective study. Ann R Coll Surg Engl 76(6):418-419

26. Linder MM, Wacha H, Feldmann U, Wesch G, Streifensand RA, Gundlach E (1987) The Mannheim peritonitis index. An instrument for the intraoperative prognosis of peritonitis. Chirurg 58(2):84-92

27. Dindo D, Demartines N, Clavien PA (2004) Classification of surgical complications: a new proposal with evaluation in a cohort of 6336 patients and results of a survey. Ann Surg 240(2):205-213. https://doi.org/10.1097/01.sla.0000133083.54934.ae

28. Liu T, Liang W, Zhong H, He J, Chen Z, He G, Song T, Chen S, Wang P, Li J, Lan Y, Cheng M, Huang J, Niu J, Xia L, Xiao J, Hu J, Lin L, Huang Q, Rong Z, Deng A, Zeng W, Li J, Li X, Tan X, Kang 
M, Guo L, Zhu Z, Gong D, Chen G, Dong M, Ma W (2020) Risk factors associated with COVID-19 infection: a retrospective cohort study based on contacts tracing. Emerg Microbes Infect 9(1):15461553. https://doi.org/10.1080/22221751.2020.1787799

29. Xu L, Mao Y, Chen G (2020) Risk factors for 2019 novel coronavirus disease (COVID-19) patients progressing to critical illness: a systematic review and meta-analysis. Aging (Albany NY) 12(12): 12410-12421. https://doi.org/10.18632/aging.103383

30. Slim K, Veziant J (2020) Urgent digestive surgery, a collateral victim of the COVID-19 crisis? J Visc Surg 157(3S1):S5-S6. https://doi.org/10.1016/j.jviscsurg.2020.04.001

31. Gao Z, Li M, Zhou H, Liang Y, Zheng C, Li S, Zhang T, Deng W (2020) Complicated appendicitis are common during the epidemic period of 2019 novel coronavirus (2019-nCoV). Asian J Surg 43: 1002-1005. https://doi.org/10.1016/j.asjsur.2020.07.019

32. Cano-Valderrama O, Morales X, Ferrigni CJ, Martin-Antona E, Turrado V, Garcia A, Cunarro-Lopez Y, Zarain-Obrador L, Duran-Poveda M, Balibrea JM, Torres AJ (2020) Acute care surgery during the COVID-19 pandemic in Spain: changes in volume, causes and complications. A multicentre retrospective cohort study. Int J Surg 80:157-161. https://doi.org/10.1016/j.ijsu.2020.07.002
33. Collard M, Lakkis Z, Loriau J, Mege D, Sabbagh C, Lefevre JH, Maggiori L (2020) Antibiotics alone as an alternative to appendectomy for uncomplicated acute appendicitis in adults: changes in treatment modalities related to the COVID-19 health crisis. J Visc Surg 157(3S1):S33-S42. https://doi.org/10.1016/j.jviscsurg.2020.04.014

34. Podda M, Cillara N, Di Saverio S, Lai A, Feroci F, Luridiana G, Agresta F, Vettoretto N, Appendicitis ASGoA (2017) Antibiotics-first strategy for uncomplicated acute appendicitis in adults is associated with increased rates of peritonitis at surgery. A systematic review with meta-analysis of randomized controlled trials comparing appendectomy and non-operative management with antibiotics. Surgeon 15(5): 303-314. https://doi.org/10.1016/j.surge.2017.02.001

35. Harnoss JC, Zelienka I, Probst P, Grummich K, Muller-Lantzsch C, Harnoss JM, Ulrich A, Buchler MW, Diener MK (2017) Antibiotics versus surgical therapy for uncomplicated appendicitis: systematic review and meta-analysis of controlled trials (PROSPERO 2015: CRD42015016882). Ann Surg 265(5):889900. https://doi.org/10.1097/SLA.0000000000002039

Publisher's note Springer Nature remains neutral with regard to jurisdictional claims in published maps and institutional affiliations.

\section{Affiliations}

Arnulf G. Willms ${ }^{1}$ (D) $\cdot$ Karl J. Oldhafer ${ }^{2} \cdot$ Sophie Conze ${ }^{1} \cdot$ Wolfgang E. Thasler ${ }^{3} \cdot$ Christian von Schassen $^{4}$. Thorsten Hauer $^{5} \cdot$ Tobias Huber $^{6} \cdot$ Christoph-Thomas Germer $^{7}$. Simone Günster ${ }^{8}$. Dirk R. Bulian ${ }^{9} \cdot$ Zarah Hirche $^{10}$. Jörg Filser ${ }^{11}$. Gregor A. Stavrou ${ }^{12}$. Martin Reichert ${ }^{13}$. Patrizia Malkomes ${ }^{14}$. Steffen Seyfried ${ }^{15} \cdot$ Tobias Ludwig $^{16}$. Hans C. Hillebrecht ${ }^{17}$. Dimitrios Pantelis ${ }^{18}$. Stefanie Brunner ${ }^{19} \cdot$ Wilm Rost $^{4} \cdot$ Johan F. Lock ${ }^{7}$. CAMIN Study Group

1 Klinik für Allgemein- und Viszeralchirurgie, Thoraxchirurgie, Bundeswehrzentralkrankenhaus Koblenz, Koblenz, Germany

2 Klinik für Leber-, Gallenwegs- und Pankreaschirurgie, Asklepios Klinik Barmbeck, Hamburg, Germany

3 Abteilung für Allgemein-, Viszeral-, Thorax- und Minimalinvasive Chirurgie, Rot-Kreuz-Klinikum München, München, Germany

4 Klinik für Allgemein- Viszeral- und Thoraxchirurgie, Bundeswehrkrankenhaus Hamburg, Hamburg, Germany

5 Klinik für Allgemein-, Viszeral- und Thoraxchirurgie, Bundeswehrkrankenhaus Berlin, Berlin, Germany

6 Klinik für Allgemein-, Viszeral-und Transplantationschirurgie, Universitätsmedizin Mainz, Mainz, Germany

7 Klinik und Poliklinik für Allgemein-, Viszeral-, Transplantations-, Gefäß- und Kinderchirurgie, Universitätsklinikum Würzburg, Würzburg, Germany

8 Operatives Zentrum für Allgemeinchirurgie, Klinikum Fürth, Fürth, Germany

9 Klinik für Viszeral-, Tumor-, Transplantations- und Gefäßchirurgie, Kliniken der Stadt Köln, Standorte Merheim und Holweide, Köln, Germany

10 Klinik für Allgemein-, Viszeral- und Thoraxchirurgie, Klinikum Ludwigshafen am Rhein, Ludwigshafen, Germany
11 Klinik für Allgemein-, Viszeral- und Thoraxchirurgie, InnKlinikum Altötting und Mühldorf, Altötting, Germany

12 Klinik für Allgemein- und Viszeralchirurgie, Thoraxchirurgie, Chirurgische Onkologie, Klinikum Saarbrücken, Saarbrücken, Germany

13 Klinik für Allgemein-, Viszeral-, Thorax-, Transplantations- und Kinderchirurgie, Universitätsklinikum Gießen, Gießen, Germany

14 Klinik für Allgemein-, Viszeral- und Transplantationschirurgie, Universitätsklinikum Frankfurt, Frankfurt, Germany

15 Chirurgische Klinik, Universitätsmedizin Mannheim, Mannheim, Germany

16 Abteilung für Allgemein-, Viszeral-, Gefäß- und Transplantationschirurgie, Universitätsmedizin Rostock, Rostock, Germany

17 Klinik für Allgemein- und Viszeralchirurgie, Universitätsklinikum Freiburg, Freiburg, Germany

18 Abteilung für Allgemein- und Viszeralchirurgie, GFO Kliniken Bonn, Bonn, Germany

19 Klinik und Poliklinik für Allgemein-, Viszeral-, Tumor- und Transplantationschirurgie, Uniklinik Köln, Köln, Germany 